Nuclear Data Requirements for the
Production Of Medical Isotopes in
Fission Reactors and Particle Accelerators

M. A. Garland,

R. E. Schenter,

R. J. Talbert,

S. G. Mashnik,

W. B. Wilson

3rd International Conference on Isotopes

August 31, 1999 


\title{
NUCLEAR DATA REQUIREMENTS FOR THE PRODUCTION OF MEDICAL ISOTOPES IN FISSION REACTORS AND PARTICLE ACCELERATORS
}

\author{
MARC A. GARLAND, ROBERT E. SCHENTER, AND ROBERT J. TALBERT \\ Pacific Northwest National Laboratory, Richland, Washington 99352, USA \\ E-mail: Marc.Garland@pnl.gov,_re_schenter@pnl.gov,_bob.talbert@pnl.gov \\ STEPAN G. MASHNIK AND WILLIAM B. WILSON \\ Los Alamos National Laboratory, Los Alamos, New Mexico 87545, USA \\ E-mail: mashnik@t2y.lanl.gov,_wbw@lanl.gov
}

\begin{abstract}
Simulations of isotope-production irradiations of targets in the radiation environments of fission reactors or particle accelerators require the evaluation of proton and/or neutron particle fluxes within the target and the integration of these with appropriate cross-section data. In fission reactors, proton fluxes are typically considered negligible and the approach reduces to neutron reactions at energies below the upper extents of the fission spectrum at which neutrons are born -10 to 15 $\mathrm{MeV}$. In particle accelerator target simulations, the secondary neutron flux can provide considerable production and/or collateral target activation. Where target and product nuclides are separated in $\mathrm{Z}$ and $\mathrm{A}$, the relative contributions of neutron and proton reactions may not be apparent. Through decades of effort in nuclear data development and simulations of reactor neutronics and accelerator transmutation, a collection of reaction data is continuing to evolve with the potential of direct applications to the production of medical isotopes. At Los Alamos the CINDER'90 code and library have been developed for nuclide inventory calculations using neutron-reaction $(\mathrm{En} \leq 20 \mathrm{MeV})$ and/or decay data for 3400 nuclides; coupled with the LAHET Code System (LCS), irradiations in neutron and proton environments below a few $\mathrm{GeV}$ are tractable; additional work with the European Activation File, the HMS-ALICE code and the reaction models of MCNPX (CEM95, BERTINI, or ISABEL with or without preequilibrium, evaporation and fission) have been used to produce evaluated reaction data for neutrons and protons to $1.7 \mathrm{GeV}$. At the Pacific Northwest National Laboratory, efforts have focused on production of medical isotopes and the identification of available neutron reaction data from results of integral measurements.
\end{abstract}

\section{Introduction}

Medical radioisotope production is receiving increased attention due to the many advances in nuclear medicine. In addition to further development in diagnostic nuclear medicine, pioneering work is being done in therapeutic applications of radioisotopes. For example, radiolabeled monoclonal antibodies are being used to treat leukemia and lymphoma, brachytherapy is being used 
to treat prostate cancer, radioactive stents are being used to prevent restenosis (reclogging of arteries) following angioplasty treatment of coronary heart disease, and radioisotopes are being used to palliate the excruciating bone pain associated with metastatic cancer.

Continued success in developing cures for cancer and ultimately in treating a large number of cancer patients is adversely impacted by this lack of knowledge of certain neutron capture cross sections for medically important radioisotopes. Without this data, medical radioisotope production cannot be optimized. Optimization is not only critical for economic reasons, but also for applications requiring the production of very high specific activity radioisotopes. In many cases, trial and mixed success is "de rigueur" for producing certain radioisotopes of medical significance.

\section{Reactor-Spectrum Data Needs}

As an example, the thermal and resonance integral cross sections are known for ${ }^{186} \mathrm{~W}$ and ${ }^{187} \mathrm{~W}$, but not for ${ }^{188} \mathrm{~W}$. Thus, optimal production of the medically important radioisotope ${ }^{188} \mathrm{~W}$ may not be realized since calculations related to the design of ${ }^{186} \mathrm{~W}$ targets, their placements in a reactor and irradiation times cannot accurately be performed.

The design for a reactor focused on isotope production needs to consider the neutron cross sections of the medical radioisotopes to be produced so that proper neutronic conditions can be achieved for optimal radioisotope production. Neutron cross section information is needed to design targets (and hopefully a reactor) for the optimal production of medical radioisotopes.

Production of medical radioisotopes in fission reactor systems must be optimized with respect to several different parameters: position, target composition, density, configuration, etc. Research is required to determine the needed cross sections. Knowledge of these cross sections will benefit several practical applications and will also provide important modern data information for many isotopes previously unavailable.

The main objective of an initiative to address the cross section deficiencies is to access the cross sections that are of the greatest projected need. Table 1 identifies several medical radioisotopes that harbor deficiencies in cross section knowledge required for efficient, high specific activity production. In order to demonstrate how the lack of knowledge of the cross section impacts production results, calculations were made for six important medical isotope products. Table 2 shows these results comparing values with known and unity cross sections.

LA-UR-99-4898: submitted to World Scientific on September 27, 2018 
Table 1. Medical Isotopes with Unknown Cross-Section Data

\begin{tabular}{|c|c|c|c|l|}
\hline \hline Isotope & $\begin{array}{c}\mathrm{T}_{1 / 2} \\
\text { days })\end{array}$ & $\begin{array}{c}\sigma_{t h} \\
\text { (barns) }\end{array}$ & $\begin{array}{c}\text { R I } \\
\text { (barns })\end{array}$ & \multicolumn{1}{|c|}{ Medical Application } \\
\hline \hline${ }^{188} \mathrm{~W}$ & 69.4 & unknown & unknown & $\begin{array}{l}\text { cancer and rheumatoid arthritis therapy, } \\
\text { radiolabeled antibodies for cancer therapy }\end{array}$ \\
\hline${ }^{186} \mathrm{Re}$ & 3.72 & unknown & unknown & $\begin{array}{l}\text { prostate cancer and rheumatoid arthritis } \\
\text { therapy, radiolabeled antibodies for cancer } \\
\text { therapy, bone pain palliation }\end{array}$ \\
\hline${ }^{188} \mathrm{Re}$ & 0.71 & unknown & unknown & $\begin{array}{l}\text { medullary thyroid carcinoma therapy, bone } \\
\text { pain palliation, radiolabeled antibodies } \\
\text { for cancer therapy }\end{array}$ \\
\hline${ }^{194} \mathrm{Os}$ & $6.0 \mathrm{y}$ & unknown & unknown & radiolabeled antibodies for cancer therapy \\
\hline${ }^{193} \mathrm{Os}$ & 1.27 & 40 & unknown & cancer therapy \\
\hline${ }^{198} \mathrm{Au}$ & 2.70 & $26 \mathrm{E} 3$ & unknown & ovarian, prostate, brain cancer therapy \\
\hline${ }^{166} \mathrm{Ho}$ & 1.12 & unknown & unknown & cancer and rheumatoid arthritis therapy \\
\hline${ }^{177} \mathrm{Lu}$ & 6.71 & 1000 & unknown & $\begin{array}{l}\text { radiolabeled antibodies for cancer therapy, } \\
\text { heart disease therapy }\end{array}$ \\
\hline${ }^{153} \mathrm{Sm}$ & 1.93 & 400 & unknown & $\begin{array}{l}\text { radiolabeled antibodies for cancer therapy, } \\
\text { bone pain palliation, treatment of leukemia }\end{array}$ \\
\hline${ }^{153} \mathrm{Gd}$ & 241.6 & $2 \mathrm{E} 4$ & unknown & osteoporosis detection, SPECT imaging \\
\hline${ }^{127} \mathrm{Xe}$ & 36.4 & unknown & unknown & $\begin{array}{l}\text { neuroimaging for brain disorders, } \\
\text { neuropsychiatric disorder research, } \\
\text { SPECT imaging, lung imaging }\end{array}$ \\
\hline${ }^{125} \mathrm{Xe}$ & 0.71 & unknown & unknown & cancer therapy \\
\hline${ }^{126} \mathrm{I}$ & 13.0 & unknown & unknown & cancer therapy \\
\hline \hline
\end{tabular}

Table 2. Production Results with Known and Unity Cross Section Values

\begin{tabular}{|c|c|c|c|c|c|c|}
\hline $\begin{array}{l}\text { Product } \\
\text { Isotope }\end{array}$ & $\begin{array}{l}\text { Target } \\
\text { Isotope }\end{array}$ & $\begin{array}{l}\text { Product } \\
\text { 1-Group } \\
\text { Cross } \\
\text { Section } \\
\text { (barns) }\end{array}$ & $\begin{array}{c}\text { Target } \\
\text { 1-Group } \\
\text { Cross } \\
\text { Section } \\
\text { (barns) }\end{array}$ & $\begin{array}{c}\text { Production } \\
\text { (Ci/g-tgt) } \\
\text { Using } \\
\text { Known } \\
\text { Cross } \\
\text { Sections }\end{array}$ & $\begin{array}{l}\text { Production } \\
\text { (Ci/g-tgt) } \\
\text { Using Unity } \\
\text { Cross } \\
\text { Sections }\end{array}$ & $\begin{array}{c}\text { Ratio of } \\
\text { Unity to } \\
\text { Known } \\
\text { Cross } \\
\text { Section } \\
\text { Production }\end{array}$ \\
\hline $198 \mathrm{Au}$ & ${ }^{197} \mathrm{Au}$ & $\overline{1.62 \mathrm{E}+3}$ & $\overline{1.40 \mathrm{E}+1}$ & $\overline{6688}$ & $\overline{67.4}$ & 0.10 \\
\hline${ }^{60} \mathrm{Co}$ & ${ }^{59} \mathrm{Co}$ & $3.24 \mathrm{E}-1$ & $5.42 \mathrm{E}+0$ & 68.1 & 12.9 & 0.19 \\
\hline${ }^{125} \mathrm{I}$ & ${ }^{124} \mathrm{Xe}$ & $1.83 \mathrm{E}+2$ & $4.61 \mathrm{E}+1$ & 1190 & 151 & 0.13 \\
\hline${ }^{192} \mathrm{Ir}$ & ${ }^{191} \mathrm{Ir}$ & $2.89 \mathrm{E}+1$ & $1.53 \mathrm{E}+1$ & 545 & 47.3 & 0.087 \\
\hline${ }^{145} \mathrm{Sm}$ & ${ }^{144} \mathrm{Sm}$ & $2.06 \mathrm{E}+1$ & $1.47 \mathrm{E}-1$ & 3.91 & 30.1 & 7.7 \\
\hline${ }^{153} \mathrm{Sm}$ & ${ }^{152} \mathrm{Sm}$ & $7.66 \mathrm{E}+1$ & $3.83 \mathrm{E}+1$ & 3420 & 91.5 & 0.027 \\
\hline
\end{tabular}




\section{Medium-Energy Data Evaluations}

In the radiation environment of a proton accelerator target, neutron and proton reactions may significantly contribute to the production of the desired radionuclide. Medium-energy protons may each produce a few tens of neutrons in a high- $Z$ target, each having a significant range and contribution to particle flux. The complexities resulting from the myriad of possible reaction paths, along with spatially varying flux magnitudes and spectra, require the evaluation of pertinent cross sections and fluxes. These are evaluated in sequential calculations with the LAHET Code System LCSI - the compination of LAHET and MCNPB, or their subsequent combination in MCNPX 3 - with the CINDER'90 nuclide inventory code; reactions of protons and medium-energy neutrons are calculated with on-line nuclear models and evaluated lower-energy neutron reaction cross section are contained in the CINDER'90 library. This state-of-the-art sequence is used effectively in the analysis of medium-energy designs but requires a significant investment of $\mathrm{CPU}$ time.

Nuclear models have also been utilized with limited available measured cross section data to form evaluations for a growing number of target nuclides. Neutron and proton cross sections from threshold to $1.7 \mathrm{GeV}$ have been evaluated for the stable isotopes of $\mathrm{O}, \mathrm{F}, \mathrm{Ne}, \mathrm{Na}, \mathrm{Mg}, \mathrm{Al}, \mathrm{S}, \mathrm{Cl}, \mathrm{Ar}, \mathrm{K}, \mathrm{Zn}, \mathrm{Ga}$, $\mathrm{Ge}, \mathrm{As}, \mathrm{Zr}, \mathrm{Nb}, \mathrm{Mo}$, Xe, Cs, Ba, $\mathrm{La}$, and $\mathrm{Hg}$ - or about $30 \%$ of the naturallyoccuring stable nuclides. These evaluations have used available measured data from the LANL T-2 compilation, the evaluations of the EAF97 library for neutrons below $20 \mathrm{MeV}$, and calculations with HMS-ALICE, CEM95, 8 and the BERTINI and ISABEL models of LAHET. Samples of the data and evaluations for two of nearly 700 reactions evaluated to date are shown in Figure 1. Complete results are shown in Ref. 10.

\section{Conclusions}

The status of simulation methods and data available for the description of isotope production is fair and improving, but many additional cross section measurements and evaluations are needed. Consequently, further research in obtaining better cross section information will have positive benefits in the field of medical science.

\section{References}


1. R. E. Prael and H. Lichtenstein, "User Guide To LCS: The LAHET Code System," Los Alamos National Laboratory informal report LA-UR-893014 (Sept. 1989).

2. J. F. Briesmeister, Editor, "MCNP - A General Monte Carlo N-Particle Transport Code," Los Alamos National Laboratory Manual LA-12625-M (November 1993).

3. H. G. Hughes et al., "MCNPX For Neutron-Proton Transport," Los Alamos National Laboratory Report LA-UR-99-1935 (1999), submitted to M\&C'99, September 27-30, 1999, Madrid, Spain.

4. W. B. Wilson et al., "Accelerator Transmutation Studies at Los Alamos with LAHET, MCNP, and CINDER'90," Proceedings of the Workshop on Simulation of Accelerator Radiation Environments, January 11-15, 1993, Santa Fe, New Mexico; Los Alamos National Laboratory conference proceedings LA-12835-C (October 1994) pp.115-133; also available as Los Alamos National Laboratory informal document LA-UR-93-3080 (January 11, 1993).

5. W. B. Wilson, T. R. England and K. A. Van Riper, "Status of CINDER'90 Codes and Data," Proc. Fourth Workshop on Simulating Accelerator Radiation Environments, Sept. 14-16, 1998, Knoxville, Tenn, pp. 69-79.

6. S. G. Mashnik, A. J. Sierk, K. A. Van Riper and W. B. Wilson, "Production and Validation of Isotope Production Cross Section Libraries for Neutron and Protons to 1.7 GeV," Proc. Fourth Workshop on Simulating Accelerator Radiation Environments, Sept. 14-16, 1998, Knoxville, Tenn, pp. 151-162; Eprint nucl-th/9812071 on the LANL xxx.lanl.gov server.

7. J.-Ch. Sublet, J. Kopecky, R. A. Forrest and D. Nierop, "The European Activation File: EAF-97 REPORT File, Rev. 1," UKAEA Fusion report.

8. M. Blann and M. B. Chadwick, "New Precompound Decay Model: Angular Distributions," Phys Rev. C57, 233 (1998).

9. S. G. Mashnik, "User Manual For The Code CEM95," Joint Institute for Nuclear Research, Dubna (1995), see the Web page http://www.nea.fr/abs/html/iaea1247.htm.

10. K. A. Van Riper, S. G. Mashnik and W. B. Wilson, "Study of Isotope Production in High Power Accelerators: Detailed Report," Los Alamos National Laboratory informal report LA-UR-98-5379 (1998) (a 684 page report with 37 tables and 264 color figures available on the Web at: http://t2.lanl.gov/publications/publications.html). 

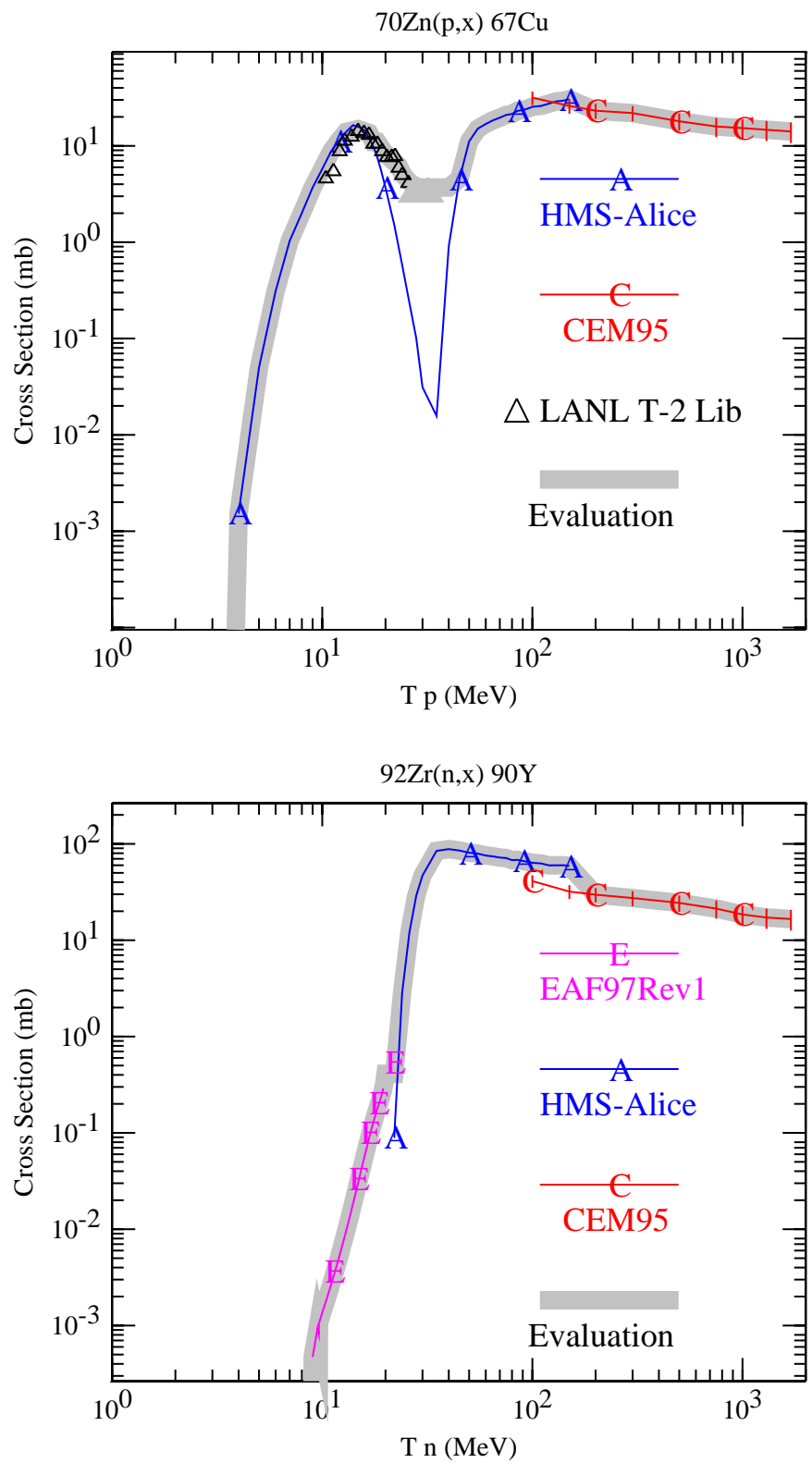

Figure 1. Samples of Data and Evaluations for $(\mathrm{p}, \mathrm{x})$ and $(\mathrm{n}, \mathrm{x})$ Reactions. 